Monografias Ambientais

(e-ISSN: 2236-1308)

REMOANFSM

\title{
A AQUARIOFILIA COMO FERRAMENTA DE EDUCAÇÃO AMBIENTAL PARA CONSERVAÇÃO DA BIODIVERSIDADE
}

\author{
Vinicius Ferreira Ardel, Solange Alves Duarte dos Santos
}

\section{RESUMO}

O presente artigo pretende mostrar como a aquariofilia pode ser uma relevante ferramenta para Educação Ambiental, um hobby que vem expandindo progressivamente no Brasil. O aquarismo, como forma de diversão, trabalho ou pesquisa, permite a observação direta dos incontáveis mistérios da natureza submarina, ao mesmo tempo que analisa a diversificada maneira de vida das espécies que nela habitam. Os conceitos teóricos das condições ambientais existentes na natureza e eventuais transformações ocorridas no meio artificial, permite ao aquarista ampliar seus conhecimentos, adquirindo noções suficientes e, ainda, presta-Ihe aptidão necessária para proporcionar o ambiente adequado as exigências vitais dos seres aquáticos. A aquariofilia na Educação Ambiental, visa a pesquisa pura e aplicada na manutenção e reprodução de organismos aquáticos em sistemas semi-fechados em associação com a preservação do meio ambiente através de atividades de repovoamento e reintrodução de organismos, bem como a conscientização da população, para a conservação da biodiversidade. Ainda, a aquariofilia pode colaborar com o ensino de parâmetros químicos, físicos e biológicos da água.

PALAVRAS-CHAVE: Educação Ambiental; Aquariofilia; Parâmetros da Água; Biodiversidade; Conscientização.

\section{ABSTRACT}

This article aims to show how the aquarium can be an important tool for Environmental Education, a hobby that has been expanding steadily in Brazil. The aquarium, as a form of entertainment, work or research, allows the direct observation of nature countless mysteries of the submarine while it analyzes the diverse ways of life of the species that inhabit it. The theoretical concepts of environmental conditions existing in nature and any changes occurring in the artificial medium, allows the hobbyist to expand their knowledge, acquire sufficient concepts, and also provides you with skills needed to provide a suitable environment for the vital requirements of aquatic life. The aquarium in Environmental Education, aims to pure and applied research in the maintenance and reproduction of aquatic organisms in semi-closed systems in association with the preservation of the environment through activities restocking and reintroduction of agencies, and public awareness for biodiversity conservation. Still, the aquarium can collaborate with the teaching of the chemical, physical and biological water.

KEYWORDS: Environmental Education; Aquarium; Parameters of Water, Biodiversity; Awareness.

\section{INTRODUÇÃO}


Um aquário é a única forma de trazer para casa um elemento vivo da natureza sem causar qualquer problema em particular. Não existe outro hobby como o aquário, que nos ofereça a possibilidade de viver diariamente em contato com a natureza, ter um aquário requer alguns conhecimentos básicos. ${ }^{1}$

Através de um tanque podemos construir, no interior de nossas casas, parte de um mundo fascinante e, até certo ponto, desconhecido. ${ }^{2}$ Um aquário é um pequeno local, a princípio artificial, mas que a partir dos primeiros dias depois de montado vai criando uma biologia própria e vai se transformando como um pequeno pedaço de rio ou de lago. Os peixes no aquário, longe dos predadores naturais, encontram um ótimo habitat para a vida, o crescimento, o desenvolvimento e para a reprodução. ${ }^{3}$

Desta forma, reagrupamos uma comunidade de peixes, corais e algas, e criamos condições biológicas e químicas artificiais, que concebemos segundo nossas ideias e conhecimentos, mas que, com o decorrer de algum tempo, segue leis vitais próprias e bem definidas. Todavia seremos nós os únicos responsáveis pela saúde e sobrevivência dos seres escolhidos para habitarem nosso ambiente artificial. O conhecimento preciso do espaço vital disponível, bem como os numerosos acessórios técnicos e produtos químicos existentes no comércio especializado, sem dúvida contribuem de maneira decisiva para o sucesso da manutenção de espécimes vivos em cativeiro. ${ }^{2}$

Muito mais que um hobby, o aquarismo sempre foi entretenimento, objeto e ferramenta de estudo. Como diversão para o público o grande número de aquários públicos pelo mundo afora, como o Museu Oceanográfico de Mônaco o Oceanário de Lisboa (o maior aquário da Europa) e o Sea World e o Living Seas, ambos em Orlando. Todos estes aquários são exemplos de empreendimentos lucrativos e que demandam mão-de-obra qualificada e multidisciplinar, são exemplos também de empresas bem administradas longevas e lucrativas. ${ }^{4}$

No Brasil existem outros exemplos, como o veterano Aquário de Santos, o Aquário do Guarujá e a mais nova iniciativa o Aquário de São Paulo. ${ }^{4}$

O aquário não é somente um objeto complementar decorativo, mas principalmente um instrumento de lapidação dos estudos científicos, tecnológicos e artísticos. Pelo estudo aprimorado e objetivo o aquarista se enriquece de conhecimentos importantes, imuniza-se contra informações controvertidas, tornando o estudo do aquarismo um assunto sério, afastando desta forma, eventual perspectiva de erro. ${ }^{2}$ O aquarismo tem importância relevante na educação ambiental. A maioria das pessoas que possuem um aquário compreende e respeita muito mais a natureza, pois sabem quão delicado é seu equilíbrio e também sabe que sua paixão pelo hobby depende da valorização e preservação das espécies e por consequência do meio ambiente. ${ }^{4}$

Através desta significação mais séria, o aquarismo se impõe com uma conotação muito mais ampla, que resulta na formação de um ser humano mais consciente no tocante à conservação do meio ambiente natural. Tal conotação tem profundo significado, pois, ao que parece, os avanços da tecnologia atual colocam as necessidades básicas de preservação ambiental relegadas a um plano secundário. ${ }^{2}$ Hoje o aquarismo sofre muito com a expansão das fronteiras agrícolas, alterações dos cursos de água, poluição e pesca excessiva, enfim, com a degradação do Planeta Terra. Como consequência, surgiu a necessidade de se cultivar as espécies em cativeiro, o que recebeu o nome de aquicultura, e se tornou o maior responsável pelo abastecimento do comércio do aquarismo. Sendo este um empreendimento lucrativo e perfeitamente sustentável pelo meio ambiente. ${ }^{5}$

A plena consciência de que um aquarismo sadio resulta invariavelmente num consenso humanístico, que nos coloca em guarda contra os perigos da aniquilação do meio ambiente, e nos 
alerta para as necessidades básicas que têm os diversos espécimes para se desenvolverem ou simplesmente sobreviverem em paz no nosso planeta. ${ }^{2}$

É necessário ter a compreensão dos fenômenos ambientais para entender o que acontece dentro de um aquário, como $\mathrm{PH}$, dureza da água, matéria orgânica, volume, vazão, reprodução e poluição. $^{4}$

Várias espécies de peixes da Região do Cerrado e da Mata Atlântica já estariam extintas se não fosse pela iniciativa própria e apaixonada de muitos aquaristas que se interessaram pela preservação e manutenção destes pequenos peixes, estudando-os e desenvolvendo técnicas de

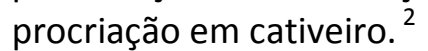

Esta atividade amadora é desenvolvida já há muito tempo no mundo inteiro e no Brasil há mais de trinta anos, quando o único preocupado em preservar era o próprio aquarista. Muito antes de se pensar em criar peixes e camarões para alimentação humana em grandes fazendas aquáticas, o homem já criava peixes em cativeiro por puro amor à natureza e hoje esta atividade fornece conhecimento e tecnologia para aumentar as fontes de produção de alimentos. ${ }^{2}$

Foi à produção de peixes e outros organismos aquáticos em cativeiro - aquários, que salvou muitas espécies da extinção, e hoje promove emprego e sustento para algumas populações ribeirinhas que viram a fonte natural do seu sustento esgotar. ${ }^{2}$

Os peixes que são comercializados nas lojas de animais são, em sua grande maioria, fruto de criatórios, portanto o aquarismo é um hobby ecológico, pois nos proporciona conhecer a ecologia aquática, e nos dias de hoje é muito importante aprender a conhecer para preservar. ${ }^{2}$

A quantidade de água existente no nosso planeta é considerável cerca de $70 \%$ de toda superfície da Terra. Nenhum outro planeta do sistema solar apresenta características semelhantes, e, toda sobrevivência e evolução da vida animal e vegetal depende diretamente deste precioso componente. Na água está hipotecada a possibilidade de sobrevivência de todos os organismos vivos das gerações futuras. Mas o nosso planeta azul está ameaçado. ${ }^{2}$

Até certo ponto, isto vem ao encontro aos anseios da nossa geração, mas nessa fase transitória observa-se que as forças naturais de biodegradação vão perdendo sua potência depuradora face a quantidade de poluentes que estão sendo lançados nas águas.

Não podemos nos omitir que gerações futuras nos apontarão como responsáveis diretos do aniquilamento do meio ambiente. ${ }^{2}$

A água é o principal sustentáculo da vida neste planeta. É preciso reavaliar o progresso e o alto preço que estamos pagando e, principalmente, pela vultosa dívida que deixaremos de herança. $^{2}$

O aquário é um pequeno ecossistema que deve ser aprimorado de forma a aproximar-se ao máximo das condições ambientais que os animais encontram na natureza. $O$ aquarista, antes de tudo, deve ser um observador atento a todas as formas manifestas de vida no seu aquário. ${ }^{2}$

Nos últimos anos, muitas espécies de animais exóticos tornaram-se populares. No entanto, isto não foi acompanhado, na maioria dos países, por um desenvolvimento paralelo da legislação. Esta carência de leis, assim com descaso na hora de aplicá-las, provocam numerosas questões éticas, especialmente no que se refere a saúde pública, bem estar animal e conservação da natureza. ${ }^{\top}$

Os peixes de aquário são um dos grupos de animais doméstico mais extensões no mundo, com milhares de espécies que compões o passa tempo dos aquários de água doce e salgada. 0 encanto deste passa tempo para muitos proprietários de peixes é a diversidade das formas e cores, o comportamento e as estratégias reprodutivas. ${ }^{7}$ 
Mantido tanto em aquários de água salgada como de água doce, mesmo que não sejam animais de companhia no sentido mais amplo da palavra, são considerados aptos para todo o tipo de pessoa. Os peixes estão muitos mais restritos ao seu ambiente do que a maioria das espécies terrestres. A água, o solvente universal é o meio no qual o peixe deve viver e respirar. Portanto, a qualidade de água é um determinante principal de sua saúde e enfermidade. Devido aos peixes serem poiquilotérmicos (sangue frio), a eficiência do metabolismo e a função imune dependem estreitamente da temperatura, ambiente e de sua relativa estabilidade. ${ }^{7}$

Ecologia é a ciência que estuda o funcionamento interno da natureza. A palavra ecologia deriva do termo grego Oikos que significa "espaço vital". ${ }^{2}$

Todo organismo vivo necessita para sua sobrevivência de uma certa gama de estímulos e recursos; luz, alimentos, água, oxigênio, calor e substâncias químicas integram os componentes básicos para o desenvolvimento das diversas formas de vida da biosfera. ${ }^{2}$

De maneira surpreendente, as propriedades de água no estado líquido parecem ter sido concebidas pela natureza com a finalidade específica de tornar o mundo hospitaleiro e viável ao advento da vida. ${ }^{7}$

Não se deve subestimar a importância da qualidade da água. Deve-se lembrar que o peixe vive, come, dorme, excreta materiais de dejetos e esse reproduz tudo no mesmo meio líquido, a água. Esta é um forte solvente, onde pode dissolver e formar muitas substâncias químicas diferentes, muitas das quais pode ser muito prejudiciais para os peixes na maioria dos sistemas de aquários, os seguintes parâmetros de qualidade de água devem ser controlados: ${ }^{7}$

Oxigênio Dissolvido (OD): A quantidade de oxigênio dissolvido na água depende da pressão parcial do oxigênio na atmosfera, o qual varia com a altitude, temperatura da água e quantidade de substâncias dissolvidas na água. Comparando com o ar, a água possui uma quantidade (ou pressão parcial) muito menor de oxigênio. ${ }^{8}$

As águas mais frias podem ter mais oxigênio que as mais quentes. Por exemplo, a água doce a 15 으 torna-se saturada a $9,76 \mathrm{mg} / \mathrm{L}(\mathrm{ppm})$, enquanto a água a $30 \circ \mathrm{C}$ somente pode ter 7,53 $\mathrm{mg} / \mathrm{L}(\mathrm{ppm})$ de oxigênio. A maioria de peixes de água quente necessita de pelo menos $1 \mathrm{ppm}$ para sobreviver, porém deve ter pelo menos 4 ppm ou mais para vingar. ${ }^{7}$

pH: A concepção de pH vem do latim pondus hidrgenii, que significa peso do íon de hidrogênio. ${ }^{2} \mathrm{Em}$ todo caso, o valor do $\mathrm{pH}$ é usado para indicar se a substância é neutra, ácida ou alcalina. A escala do pH é dividida entre 0 a 14: $\mathrm{pH} 7$ é neutro, entre 0 a 6.9 é um indicador de valores ácidos e entre 7.1 a 14 é indicador de valores base ou alcalinos. Qualquer destes valores pode ser facilmente ministrado no aquário usando líquidos indicadores apropriados. ${ }^{1}$

Temperatura: Os peixes tropicais tem um nível bem estreito de tolerância térmica. As temperaturas de $23,8-26,6$ ○C são ótimas para a maioria das espécies, ainda que muitas possam tolerar níveis mais baixos ou altos com aclimatação apropriada. ${ }^{7}$

Ciclo do nitrogênio: Naturalmente, é muito difícil evitar eventuais depósitos de restos orgânicos. Devemos notar que parte da alimentação consumidas pelos peixes não é totalmente digerida, como consequência desta constante sedimentação de produtos orgânicos, temos a formação dos compostos nitrogenados. Na degradação dos produtos decompostos pelas bactérias (nitrobactérias e nitrossomos), as reações químicas resultantes são de oxidação, temos que os nitritos ( NO2 ) são oxidados e transformados pelas bactérias denitrificantes (nitrobactérias) em nitratos ( NO3). Consideramos de especial importância, para o funcionamento do aquário, a presença destas bactérias em quantidade suficiente, para degradação das substâncias orgânicas eventuais na composição da água. As nitrissomonas e nitobactérias são bactérias aeróbicas, tendo 
em vista suas necessidades vitais de oxigênio, do qual se utilizam para consumir e transformar substâncias nitrogenadas. ${ }^{2}$

Dureza: A dureza da água é determinada pelo conteúdo de sais Ca2+ e $\mathrm{Mg} 2+.{ }^{8}$ Além dos sais, de cálcio e magnésio, quase todas as águas contém bicarbonatos, cuja a presença se reflete no valor do $\mathrm{KH}^{1}{ }^{1}$

Os bicarbonatos tem um papel importante no aquário, pois desempenham a função de tampão do $\mathrm{pH}$ e evitam uma alteração demasiada grande e rápida do valor do $\mathrm{pH}$. Devido à relação estreita entre o valor $\mathrm{KH}$ e o valor $\mathrm{pH}$, a dureza em carbonatos também influencia diretamente o bem estar de todos os organismos do aquário. Para aquários de água doce com peixes comuns teremos a água com $\mathrm{KH}$ entre 4 e $10 .^{1}$

Alcalinidade: A alcalinidade pode ser definida como "a capacidade neutralizante de uma extensão de água contra os ácidos". A alcalinidade é uma medida dos compostos que se podem unir aos ácidos (íons $\mathrm{H}+$ ) e, assim, prevenir maiores oscilações no pH. É desejável a alcalinidade maior que 50 ppm, já que as águas com alcalinidade menos que 50 ppm podem levar alterações rápidas e danosas ao $\mathrm{pH}^{7}$

Salinidade: É uma medida dos sais totais dissolvidos na água. A água do mar contém muitos íons diferentes, vários deles importantes para saúde das espécies marinhas. O cloreto de sódio( $\mathrm{NaCl}$ ) é um sal comumente adicionado aos sistemas de água doce para auxiliar na osmoregulação. ${ }^{7}$

Dióxido de Carbono: Mesmo em ambientes homogêneos podem ocorrer variações na pressão parcial de $\mathrm{CO} 2 .^{8}$ Quando falamos de dióxido de carbono ou para sermos mais exatos do $\mathrm{CO} 2$, deve fazer-se uma distinção entre aquários de água doce e aquários de água salgada. ${ }^{8}$

O CO2 é um ácido que está presente no ar e é produzido em todos os aquários, entre outras coisas por peixes, bactérias e microorganismos. Este ácido atua no $\mathrm{pH}$ e reduz o seu valor, caso não seja consumido ou expelido. ${ }^{1}$

Cloro/tosilcloraminas: Estes componentes químicos costumam ser agregados a água das redes para matar microorganismos danosos. Como regra geral qualquer quantidade mensurável deve ser considerada tóxica. Pessoas que utilizam água de rede para seu aquário devem neutralizar ou eliminar o cloro e as tosilcloraminas antes de utilizar a água. ${ }^{7}$

Nitogênio (N2): O nitrogênio é um dos nutrientes mais importantes que faz parte da complexa cadeia molecular proteica da estrutura dos vegetais sendo muitos deles utilizados na alimentação básica de alguns peixes. Na natureza o nitrogênio aparece nas águas dos rios lagos, oceanos etc. $O$ processo que intervém para sua utilização nas diferentes formas é conhecido como "ciclo do nitrogênio" e sempre sua transformação é realizada através do advento de bactérias. ${ }^{2}$

Metais Pesados: O chumbo, cobre e zinco das tubulações antigas ou de outras fontes podem ser tóxicos para os peixes, principalmente se a água tem baixa alcalinidade e $\mathrm{pH}$. Os metais pesados lesam as guelras, rins e fígado e o cobre é imunossupressor. ${ }^{7}$

Sulfeto de Hidrogênio: Um odor semelhante a ovo podre. Pode ser mortal para os peixes em quantidades muito baixas $(0,002 \mathrm{ppm}$ ou mais) e é mais tóxico em pH mais baixo e temperaturas mais altas. É recomendado um forte arejamento para eliminar o gás antes de utilizála. ${ }^{1}$

Ferro: Concebido para o cultivo e fortalecimento de plantas de aquário. ${ }^{1}$

Quando o ferro se desprende da solução como dióxido de ferro, observa-se um precipitado avermelhado dentro do reservatório de água o excesso de ferro pode causar problemas nas guelras dos peixes. ${ }^{7}$ 


\section{METODOLOGIA}

O caminho metodológico compreendeu revisão bibliográfica de livros e artigos recentes publicados em revistas de aquarismo por biólogos.

Após levantamento bibliográfico, será proposto aulas em diferentes classes do ensino fundamental e médio com termos teóricos sobre biótopos aquáticos; aulas com auxilio áudio visual com documentários e apresentações em Power Point; uma semana biocultural sobre educação ambiental, e há montagem de um tanque na escola para observação, manutenção e compreensão dos alunos sobre o tema abordado.

\section{RESULTADOS ESPERADOS}

Espera-se que os alunos do Ensino Fundamental e Ensino Médio desenvolvam gradualmente o conhecimento e conscientização sobre a importância de atitudes menos impactantes ao meio ambiente, e a responsabilidade social em suas atitudes para preservação das espécies e de seus biótopos naturais.

\section{REFERÊNCIAS BIBLIOGRÁFICAS}

1. O AQUÁRIO: A NATUREZA VIVA EM SUA CASA. PRODAC; P. 3, 18, 19, 24. 2008.

2. NACCARATO W.; BROTTO R.O. O AQUÁRISMO MARINHO: TEORIA E PRÁTICA. SÃO PAULO BRASIL: MARAZUL; P. 5, 17, 18, 19, 56, 69, 74, 75; 1990.

3. TALARICO A.; REV. AQUA MAGAZINE; ED. 2; 2006.

4. SILVA M.M.; REV. AQUARISTA JUNIOR; ED. 123; AGO - SET / 2008.

5. GOMES S.; O AQUÁRIO MARINHO \& AS ROCHAS VIVAS; 1996, REVISADO EM 1999.

6. ANDREWS A.; EXELL A.; CARRINGTON N.; THE MANUAL OF FISH HEALTH; SALAMANDER BOOKS; 1988.

7. AGUILAR R.; HERNÁNDEZ-DIVERS S.M.; HERNÁNDEZ-DIVERS S.J.; ANIMAIS EXÓTICOS: ATLAS DE MEDICINA, TERAPÊUTICA E PATOLOGIA DE. SÃO CAETANO DO SUL - SÃO PAULO. INTERBOOK; P. $17,81,82,83,85,86 ; 2007$.

8. BALDISSEROTTO B. FISIOLOGIA DE PEIXES APLICADA À PISCICULTURA. SANTA MARIA; EDITORAUFSM; P. 53, 74, 125. 2009 